Study of Transport Behavior and Conversion Efficiency in Pillar Structured Neutron Detectors

R.J. Nikolic

May 1, 2007 
This document was prepared as an account of work sponsored by an agency of the United States Government. Neither the United States Government nor the University of California nor any of their employees, makes any warranty, express or implied, or assumes any legal liability or responsibility for the accuracy, completeness, or usefulness of any information, apparatus, product, or process disclosed, or represents that its use would not infringe privately owned rights. Reference herein to any specific commercial product, process, or service by trade name, trademark, manufacturer, or otherwise, does not necessarily constitute or imply its endorsement, recommendation, or favoring by the United States Government or the University of California. The views and opinions of authors expressed herein do not necessarily state or reflect those of the United States Government or the University of California, and shall not be used for advertising or product endorsement purposes.

This work was performed under the auspices of the U.S. Department of Energy by University of California, Lawrence Livermore National Laboratory under Contract W-7405-Eng-48. 
ENGINEERING@LLNL

Engineering

FY08 LDRD-ER Proposal

\section{Study of Transport Behavior and Conversion Efficiency in Pillar Structured Neutron Detectors}

Principal Investigator: Rebecca Nikolic

Engineering Directorate 


\title{
Table of Contents
}

\section{Problem Definition and Relevance}

\author{
2. Proposed Work and Uniqueness
}

3. Accomplishments

4. Project Plan, Deliverables and Milestones

5. Principal Investigator and Team

\author{
6. Funding
}

7. Exit Strategy

8. Appendices

\subsection{References \\ 8.2. Publications on Pillar Detector}

\begin{abstract}
This document was prepared as an account of work sponsored by an agency of the United States Government. Neither the United States Government nor the University of California nor any of their employees, makes any warranty, express or implied, or assumes any legal liability or responsibility for the accuracy, completeness, or usefulness of any information, apparatus, product, or process disclosed, or represents that its use would not infringe privately owned rights. Reference herein to any specific commercial product, process, or service by trade name, trademark, manufacturer, or otherwise, does not necessarily constitute or imply its endorsement, recommendation, or favoring by the United States Government or the University of California. The views and opinions of authors expressed herein do not necessarily state or reflect those of the United States Government or the University of California, and shall not be used for advertising or product endorsement purposes. This work was performed under the auspices of the U.S. Department of Energy by University of California, Lawrence Livermore National Laboratory under Contract W-7405-Eng-48, UCRL-TR-230619.
\end{abstract}




\title{
Study of Transport Behavior and Conversion Efficiency of Pillar Structured Neutron Detectors
}

\author{
Principal Investigator: Rebecca Nikolic ENG \\ Co-investigators: Adam Conway ENG,Tzu-Fang Wang CMLS \\ Prof. Barry Cheung, Nirmalendu Deo, University of Nebraska-Lincoln
}

\section{Executive Summary}

Room temperature, high efficiency and scalable radiation detectors can be realized by manipulating materials at the micro scale. With micro-semiconductor-pillars, we will advance the thermal neutron detection efficiency of semiconductor detectors to over $70 \%$ with $50 \mu \mathrm{m}$ in detector thickness. New material science, new transport behavior, neutron to alpha conversion dynamics and their relationship with neutron detection will be discovered with the proposed structures.

\section{Problem Definition and Relevance}

Radiation detection requires both neutron and gamma detectors that are inexpensive, ambient temperature, high efficiency and robust. Such detectors do not currently exist because of lack of detector materials that satisfy these stringent requirements. For neutron detectors ${ }^{3} \mathrm{He}$ detectors are currently used which have major fieldability issues. New materials and device structures are needed for revolutionary improvement in radiation detectors. By applying micro technology methods to the area of neutron detection we will be able to make revolutionary improvements in the device efficiency and fieldability.

The solution to the radiation detector materials problem is expected to have significant impact to the Department of Homeland Security in the development of detectors with the following requirements: compact, efficient, inexpensive, and operational at ambient temperature. These detectors are required for the detection of special nuclear materials as well as radiological dispersal devices. The multi-disciplinary nature of this work and the relevance to national security strongly suggest that it be carried out at a National Laboratory. This project aligns with the Engineering Focus Area of "Micro/Nano-Devices and Structures" in addressing radiation and nuclear materials detection. The proposed solution has a large potential payoff in the area of national security. If all of the requirements in our proposed device can be met, these detectors would be manufactured by partnering with an industrial collaborator and readily deployed to many agencies.

\section{Proposed Work and Uniqueness}

There exists a significant technology gap in thermal neutron detectors that have both a small device footprint and high efficiency. These devices are needed for detection of special nuclear materials. Conventional ${ }^{3} \mathrm{He}$ tube neutron detectors can achieve very high thermal neutron detection efficiency, for example, a 2" diameter tube filled with 10 $\mathrm{atm}{ }^{3} \mathrm{He}$ gas can reach $>80 \%$ detection efficiency. However, for long term stability (leakage, buildup of electronegative poison in the gas) as well as inconvenience in the replacement of very pure ${ }^{3} \mathrm{He}$ gas, the detector normally operates at a lower pressure setting thereby reducing the efficiency to $\sim 15-30 \%$. For handheld operation, the common 1" tubes are normally used yielding a thermal neutron detection efficiency of about $10-15 \%$. Furthermore, the use of these proportional counter type devices is encumbered by the required high voltage operation $(1000 \mathrm{~V})$, sensitivity to microphonics, large device footprint, and high pressure; resulting in significant complications in air transport and deployment.

One approach to this dilemma is a solid-state planar-structured device [1][2], as illustrated in Figure 1a, in which a semiconductor is coated with the converter material. Boron $10\left({ }^{10} \mathrm{~B}\right)$ is frequently used as a converter material due to its excellent thermal neutron cross-section. However, these devices are limited in efficiency due to the conflicting requirements of the ${ }^{10} \mathrm{~B}$ neutron converter material. The thermal neutron ${ }^{10} \mathrm{~B}$ reaction which populates mostly to the first excited state of ${ }^{7} \mathrm{Li}$, produces an alpha particle $(1.47 \mathrm{MeV})$ and ${ }^{7} \mathrm{Li}(0.84 \mathrm{MeV})$. These charged particles 
subsequently enter the semiconductor detector to create electrons and holes for generation of the electrical signal. However, these particles can travel inside the converter material only for a short distance $(3.3 \mu \mathrm{m})$. Thus, if the boron layer is too thick, the charged particles will be absorbed before they reach the semiconductor material. This is a design conundrum because the converter material needs to be sufficiently thick to capture most of the incoming thermal neutrons. This problem results in a device that has inefficient charged carrier production, which directly translates into low neutron detection efficiency.

Building up thicker regions of the converter material and at the same time not loosing these generated alpha particles is required in order to achieve a high efficiency semiconductor thermal neutron detector. One approach to this is led by a group of researchers at the University of Nebraska, which involves the use of boron carbide [3]. This is an elegant approach to detection because this material can both convert neutrons to alphas and generate an electrical signal. However, the demonstrated detector is made of mostly amorphous materials which are not single crystal; thus the transport issues of the electrons and holes in the amorphous material are of concern. Another approach, led by Doug McGregor as Kansas State University, utilizes a via hole technology to increase the adhesion of the ${ }^{10} \mathrm{~B}$ converter material to the semiconductor. However, the reported geometry increases the neutron detection efficiency to $3.9 \%$ which is only a slight increase over the efficiency of the planar device, $2.9 \%$ [4]. This "via hole" approach can be looked at as a general 3D approach to combining the converter material with the semiconductor detector device. We have developed an innovative pathway to fabricate an optimized 3D device to finally be able to deliver a high efficiency thermal neutron detector, which to date has been infeasible.

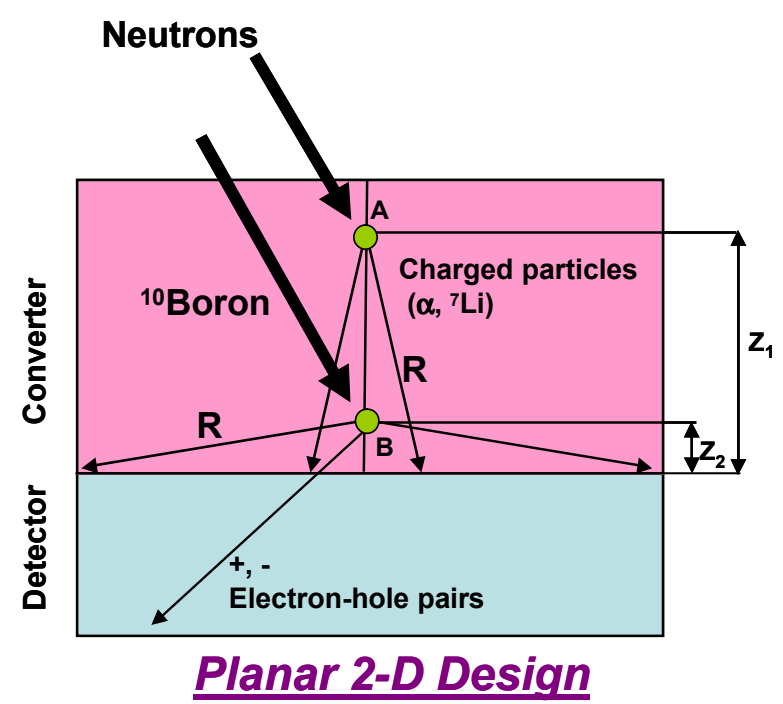

Figure 1a Schematic of planar semiconductor

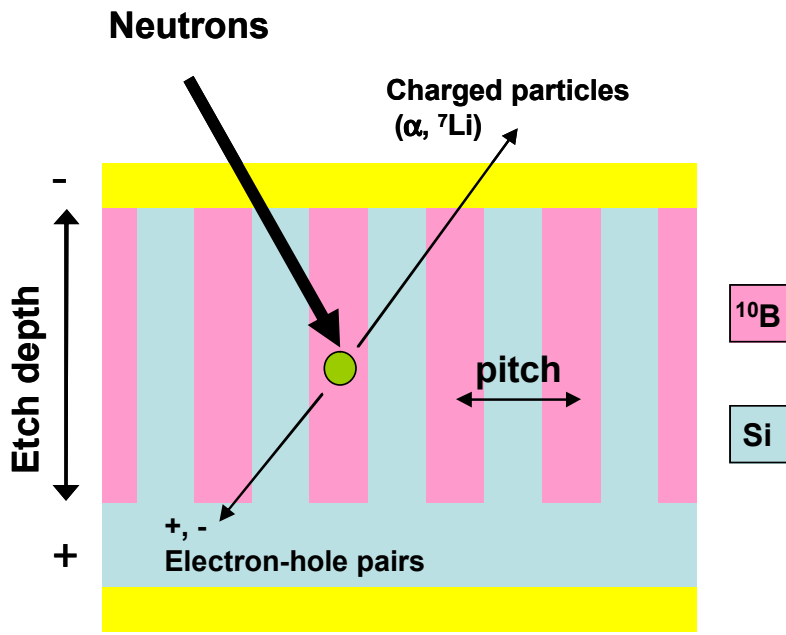

LLNL Pillar 3-D Design

Figure 1b Proposed Pillar Detector with ${ }^{10} \mathrm{~B}$ in a semiconductor detector matrix.

Our device design is shown in Figure 1b. Our proposed design is a technology advance that can increase the neutron detection efficiency from the current solid state devices 2-5\% [2] towards greater than $70 \%$. The platform consists of etched pillars of PIN diodes which are grown on a planar semiconductor substrate. The converter material and the detector material are inter-digitated such that charged particles from the thermal neutron ${ }^{10} \mathrm{~B}$ reaction have a significantly higher probability of impinging the detector material due to the close proximity. Moreover, the thickness of converter material is not limited, since the preponderance of the charged particles is detected by the adjacent pillars. In our Pillar Detector we are able to separate the constraints on the boron thickness via defining the pillar height (etch depth) which defines the material that will absorb the neutron flux. At the same time we are able to define the pitch of the pillars lithographically to have the highest possible interaction of the alphas with the semiconductor pillar to insure charged carrier generation in the pillars (see Figure 1b). 
Preliminary simulations that used results from MCNP code (to generate neutron interaction histories) then incorporated these histories into TRIM codes (for changed-particles energy loss calculations), are shown in Figure 2, indicate that the detector efficiency could reach $65 \%$ with an etch depth of $50 \mu \mathrm{m}$ and a pillar width and spacing of $2 \mu \mathrm{m}$. A further increase in efficiency (greater than $80 \%$ ) can be achieved with even smaller features.

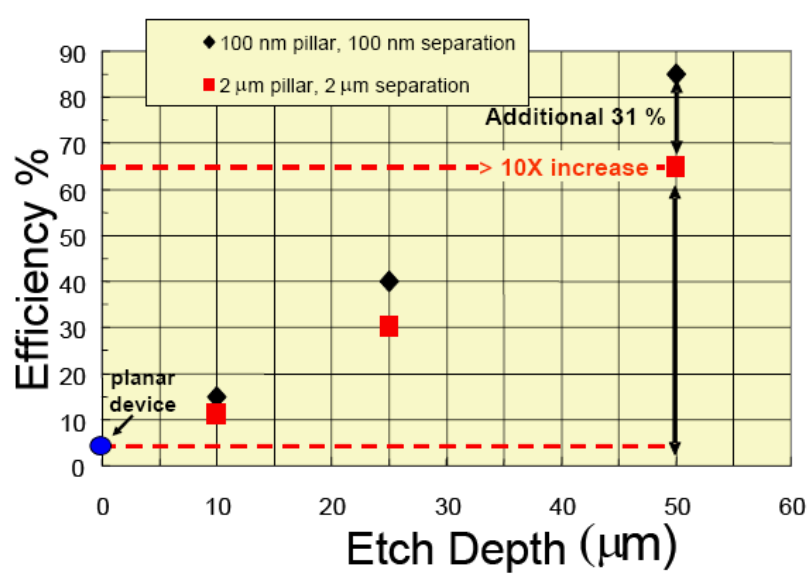

Figure 2 Efficiency versus etch depth for pillar structures of various size, filled with ${ }^{10} \mathrm{~B}$. Simulated efficiency can reach over $70 \%$.

Table 1: Comparison of ${ }^{3} \mathrm{He}$ tubes with our proposed solid state pillar structured detector.

\begin{tabular}{|c|c|c|}
\hline & ${ }^{3}$ He Tube & $\begin{array}{c}\text { LLNL 3-D Pillar } \\
\text { detector }\end{array}$ \\
\hline Efficiency (fieldable) & $<30 \%$ & $70 \%$ \\
\hline Cost & $\$ 4 \mathrm{~K}$ & $\$ 0.2 \mathrm{~K}$ \\
\hline Required voltage & $1000 \mathrm{~V}$ & $<10 \mathrm{~V}$ \\
\hline Size (probe) & $(5 \phi) \mathrm{cm} \times 10 \mathrm{~cm}$ & $1 \times 1 \times 0.1 \mathrm{~cm}^{3}$ \\
\hline $\begin{array}{c}\text { Weight (includes } \\
\text { power) }\end{array}$ & $700 \mathrm{~g}$ & $10 \mathrm{~g}$ \\
\hline Fieldability & $\begin{array}{c}\text { Microphonics, } \mathrm{HV}, \\
\text { air transport }\end{array}$ & $\begin{array}{c}\text { Not commercially } \\
\text { available }\end{array}$ \\
\hline
\end{tabular}

A comparison between our proposed device and ${ }^{3} \mathrm{He}$ tubes is shown in Table 1 . The use of ${ }^{3} \mathrm{He}$ tubes is encumbered by the required high voltage operation $(1000 \mathrm{~V})$, sensitivity to microphonics, large device footprint, and high pressure; resulting in significant complications in air transport and deployment. The crucial advantage of our Pillar Detector is that it can simultaneously meet the requirements of high efficiency and fieldability.

The work we propose in this three year project can be divided as follows:

- Boron deposition and characterization for alpha carrier generation.

- Pillar structured detector characterization for charged carrier collection.

- Device level modeling-physics for device optimization.

Boron deposition and characterization

Boron is used to convert neutrons to alpha particles. Both the deposition of boron and the characterization of the alpha generation efficiency will be carried out. These boron films should have 1) high fill-factor to minimize air gap for high alpha generation efficiency; 2) low deposition process temperature to minimize reaction between the film and the semiconductor substrate; 3) low impurity content to minimize scattering of the alpha particles; 4) high resistivity to minimize leakage current between the semiconductor pillar structures. These criteria are necessary for obtaining the desired materials with high neutron conversion efficiency for the proposed neutron detector architecture. 
Chemical vapor deposition (CVD) is the preferred method for conformal film deposition and has been demonstrated successfully on high aspect ratio structures of 1:50 [5]. Conformal film depositions demand optimization of parameters such as the precursors, surface, pressure, temperature, and other carrier gases adsorbed onto the substrate surface.

To minimize the leakage current of the as-deposited boron, we will require the boron film to have high resistivity. Though the resistivity of pure bulk boron crystal is on the order of $0.3 \mathrm{M} \Omega$, that of amorphous boron film is low $(<1$ $\mathrm{k} \Omega$, Table 2 [6]) Incorporating carbon into the amorphous thin film has been shown to increase the film resistivity by orders of magnitudes.

\section{Pillar detector characterization}

Once the alpha particles are generated within the boron material they must travel to the semiconductor pillar. These alpha particles generate electron and holes which are swept by the electric field in the intrinsic region (i-region) and create the electrical signal that shows the presence of neutrons. The transport behavior of planar devices such as MOSFETs is well understood. Our device is a vertical structure with large surface to volume ratio. Electron and hole transport in such a device is not well characterized. Both the transport behavior and leakage paths will be characterized in the Pillar Detector.

Possible leakage paths include sidewall leakage, interface and bulk leakage. We will utilize diodes with different sized geometries to evaluate the leakage current component due to area and peripheral effects. This will aid in the determination of the degree in which the passivation is adequately quenching dangling bonds at the surface of the silicon pillar. During the boron CVD process codoping of the silicon pillar may also take place. This will be quantitatively determined and intermediate dielectric spacer layers will be utilized to quench this leakage component if needed.

Device level modeling

A device level model combining MCNP, TRIM and semiconductor physics will be developed in this project to fully model the optimized device configuration and make accurate predictions on the maximum efficiency.

To summarize, the primary exploratory research components which will generate new knowledge and understanding of issues that are not clear today include:

1. Methods to etch high aspect ratio features with 2 micron feature size and deposit boron materials in these features with high fill factor.

2. Neutron to alpha conversion efficiency in high resistivity CVD boron films.

3. Electron and hole transport in vertical high aspect ratio features.

4. Model of pillar detector which includes BOTH nuclear physics and semiconductor device physics.

\section{Accomplishments [May 2006-March 2007]}

1. FY07 goal: radiation spectra of synthesized Pillar Detector (pillar height $>10 \mu \mathrm{m}$ ). Status We are working on two different structures for radiation characterization. The first structure is for neutron tests and is the structure shown in Figure $1 \mathrm{~b}$ and also Figure $3 \mathrm{~b}$. We are on target to have this structure fabricated and characterized by the end of this fiscal year. As an intermediate milestone we are also designing structures comprised of our silicon pillar detector elements with a polymer filling inbetween the elements. This allows the structure to be probed with a high energy alpha source. It is noteworthy to explain that alpha testing is a common intermediate for detector research. This is primarily due to the shallower particle range (for gamma detectors). However, in our device it is due to the complexity in detector fabrication using our filled matrix architecture. For our structure the high energy alpha test will take the place of our boron material for neutron to alpha conversion. We have fabricated and measured a pillar array device comprised of $2 \mu \mathrm{m}$ diameter pillars with $2 \mu \mathrm{m}$ separations and a etch depth of $6 \mu \mathrm{m}$ for probing with a high energy alpha source. The IV results are shown in Figure 3a and show our device has a large amount of leakage in the reverse bias which is how the device is biased as a detector. This occurred due to a soft-short between the top electrode and the intrinsic region during the device processing. As our top p+layer is only $2000 \AA$ this failure mechanism is not surprising. We have designed a modified detector structure with an additional $1 \mu \mathrm{m} \mathrm{p}+$ polysilicon layer on top of $\mathrm{p}^{+}$single crystal silicon layer to allow a more robust device for processing. We did however test a representative planar device with our epitaxial silicon PIN material with the high energy alphas and 
the resulting spectra is shown in Figure 3c, illustrating we do indeed have a test setup well characterized for our Pillar Detector and have confirmed our epitaxial material is properly functioning.

2. FY07 goal: optimization of fill efficiency (target $>80 \%$ ) of boron in high aspect ratio features. Status We have achieved a $99 \%$ fill efficiency in $6 \mu \mathrm{m}$ pillars and a $95 \%$ fill efficiency in $12 \mu \mathrm{m}$ pillars, Figure $3 \mathrm{~b}$. This has been for natural boron. We are now working with boron 10.

3. FY07 goal: alpha conversion efficiency measurement in boron films. Status We designed and setup a conversion efficiency measurement suite using a ${ }^{252} \mathrm{CF}$ neutron source with polyethylene to generate thermal neutrons. We measured a neutron to alpha particle efficiency of $1.42 \%$ for a $7300 \AA$ electron beam evaporated film. This compares well to the theoretical value of $1.46 \%$. Later this fiscal year we will have switched from natural boron to boron 10 and will apply this technique to these films.

4. FY07 goal: semiconductor model for high aspect ratio diodes. Status This task will take place Q3 and Q4 of FY07.





(A)

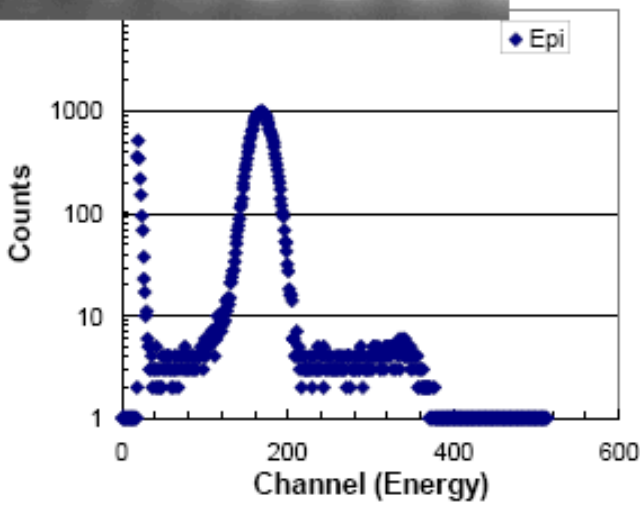

(C)

Figure 3 (A) IV of pillar array with an oxide sidewall and without (B) CVD coating of $12.5 \mu \mathrm{m}$ pillars (C) High energy alpha spectra of planar silicon PIN diode, peak at $5 \mathrm{MeV}$.

\section{Project Plan, Primary Milestones and Deliverables}

\section{Proposed work for FY08}

1. Fabrication of Pillar Detector (13 and $20 \mu \mathrm{m}$ pillar).

2. Boron 10 coatings of high aspect ratio structures.

3. Electrical, alpha and neutron measurements of Pillar Detector.

4. Refine model of transport behavior, operating characteristics and leakage paths in the Pillar Detector. 


\section{Deliverables/Milestones FOR FY08}

- Boron 10 CVD coating on flat and Pillar Detector from University of Nebraska to LLNL.

- $\quad$ Radiation spectra of 13 and $20 \mu \mathrm{m}$ etch depth Pillar Detector.

\section{Principal Investigator and Team}

We have put together a multidisciplinary team with the required disciplines in order to successfully carry out the proposed research. The PI is an expert in the area of semiconductor devices and advanced processing techniques, while Tzu-Fang Wang is an expert in nuclear physics and radiation detection. We have recently hired a Post-Doc Adam Conway who will be focused on device modeling and characterization. We have had a summer student, Daniel Heineck join us for two summers and he will be returning for the summer 2007 internship. He comes into LLNL through the summer nuclear internship program. We also have an academic collaboration with Prof. Barry Cheung from University of Nebraska-Lincoln who is an expert in inorganic chemistry and material science and will be leading the chemical vapor deposition of boron materials. Prof. Cheung has a full time post doctoral research assistant Dr. Nimalendu Deo who is an expert in chemical vapor deposition and is developing these techniques for boron deposition.

\section{Funding}

\begin{tabular}{|l|c|c|c|c|}
\hline \multirow{2}{*}{ Item } & \multicolumn{4}{|c|}{ Budget (\$K) } \\
\cline { 2 - 5 } & $\begin{array}{c}\text { FY06 } \\
(5 \text { months) }\end{array}$ & FY07 & FY08 & $\begin{array}{c}\text { FY09 } \\
(7 \text { months })\end{array}$ \\
\hline Manpower & 145 & 260 & 450 & 250 \\
\hline Sub to Nebraska & 40 & 60 & 80 & 45 \\
\hline Procurements & 10 & 10 & 10 & 10 \\
\hline Travel & 5 & 5 & 5 & 5 \\
\hline Total & 200 & 335 & 545 & 310 \\
\hline
\end{tabular}

\section{Exit Plan}

- Future funding from NNSA, NA-22 and DHS through a) strengthening effort in radiation detection technology development; b) enabling technology for fieldable and affordable radiation detectors.

- Technology transfer to commercial companies such as ORTEC, Motorola, etc. 


\section{Appendix}

\subsection{References}

1. M. Wielunski, R. Schütz, E. Fantuzzi, A. Pagnamenta, W. Wahl, J. Palfálvi, P. Zombori, A. Andrasi, H. Stadtmann and C.H.. Schmitzer, "Study of the sensitivity of neutron sensors consisting of a converter plus Si charged-particle detector," Nuclear Instruments and Methods in Physics Research A, 517, pp. 240-253, 2004.

2. H.K. Gerscha, D.S. McGregor and P.A. Simpson, "The effect of incremental gamma-ray doses and incremental neutron fluences upon the performance of self-biased ${ }^{10} \mathrm{~B}$-coated high-purity epitaxial GaAs thermal neutron detectors," Nuclear Instruments and Methods in Physics Research A 489, pp. 85-98, 2002.

3. B.W. Robertson, S. Adenwalla, A. Harken, P. Weslch, J.I. Brand, P.A. Dowben, and J.P. Claasen, "A class of boron-rich solid-state neutron detectors," Applied Physics Letters, vol. 80, no. 19, pp. 3644-3646, 2002.

4. D.S. McGregor, R.T. Klann, H.K. Gersch, E. Ariesanti, J.D. Sanders, and B. VanDerElzen, "New surface morphology for low stress thin-film-coated thermal neutron detectors," vol. 49, no. 4, pp. 1999-2004, 2002.

5. F Wiest, V. Capodieci, O. Blank, M. Gutsche, J. schulze, I. Eisele, J. Matusche, and U.I. Schmidt. "Conformal aluminum oxide coating of high aspect ratio structures using metalorganic chemical vapor deposition”. Thin Solid Films 496, 240-246 (2006).

6. V. I. Matkovich, "Boron and Refractory Borides", Springer-Verlag: New York, 1997.

\subsection{Publications, presentations}

Presentations/publications on Pillar Detector

1. "Chemical Vapor Deposition of Boron for Neutron Detector Application", N. Deo, J. Brewer, C.L. Cheung, R.J. Nikolic, C.E. Reinhardt, and T.F. Wang, MRS Spring 2007, S.F. CA.

2. "Growth of Boron Thin Films by LPCVD from Decaborane", N. Deo, J. Brewer, C.L. Cheung, R.J. Nikolic, C.E. Reinhardt, and T.F. Wang, American Chemical Society, Oct. 2006, Quincy, IL,

3. "Roadmap for high efficiency solid-state neutron detectors," R.J. Welty, C.L. Cheung, C.E. Reinhardt, T.F. Wang, invited talk at SPIE Optics East, Boston, MA, October 2005.

4. "Solid-state pillar structured thermal neutron detector," R.J. Welty, C.L. Cheung, C.E. Reinhardt, T.F. Wang, IEEE Nuclear Science Symposium, Puerto Rico, October 2005. 